\title{
Increasing Access to Care for Brazos Valley, Texas: A Rural Community of Solution
}

\author{
Whitney R. Garney, MPH, Kelly Drake, MPH, Monica L. Wendel, DrPH, MA, \\ Kenneth McLeroy, PhD, Heather R. Clark, MSPH, and Byron Ryder, BS
}

Compared with their urban counterparts, rural populations face substantial disparities in terms of health care and health outcomes, particularly with regard to access to health services. To address ongoing inequities, community perspectives are increasingly important in identifying health issues and developing local solutions that are effective and sustainable. This article has been developed by both academic and community representatives and presents a brief case study of the evolution of a regional community of solution (COS) servicing a 7-county region called the Brazos Valley, Texas. The regional COS gave rise to multiple, more localized coss that implemented similar strategies designed to address access to care within rural communities. The regional cos, known as the Brazos Valley Health Partnership, was a result of a 2002 health status assessment that revealed that rural residents face poorer access to health services and their care is often fragmented. Their localized strategy, called a health resource center, was created as a "one-stop shop" where multiple health and social service providers could be housed to deliver services to rural residents. Initially piloted in Madison County, the resource center model was expanded into Burleson, Grimes, and Leon Counties because of community buy-in at each of these sites. The resource center concept allowed service providers, who previously were able to offer services only in more populous areas, to expand into the rural communities because of reduced overhead costs. The services provided at the health resource centers include transportation, information and referral, and case management along with others, depending on the location. To ensure successful ongoing operations and future planning of the resource centers, local oversight bodies known as health resource commissions were organized within each of the rural communities to represent local COSs. Through collaboration with local entities, these partnerships have been successful in continuing to expand services and initiating health improvements within their rural communities. ( $\mathrm{J}$ Am Board Fam Med 2013;26:246-253.)

Keywords: Community Health Networks, Practice-based Research, Public Health, Rural Health

The need for adequate health care among disadvantaged and underserved populations is apparent across the United States. ${ }^{1,2}$ Rural populations specifically face substantial disparities in terms of health care and health outcomes. ${ }^{1,3,4}$ Eberhardt and

This article was externally peer reviewed.

Submitted 1 September 2012; revised 4 January 2013; accepted 9 January 2013.

From the Center for Community Health Development, Texas A\&M School of Rural Public Health, College Station, TX (WRG, KD, MLW, KM, HRC); and the Judicial and Administrative Department, Leon County Government, TX (BR).

Funding: The Brazos Valley Health Partnership (BVHP)'s early work was supported by the Healthy Community Access Program through the Bureau of Primary Care, Health Resources and Services Administration (grant no. 2 G92 colleagues ${ }^{1}$ state that rural communities encounter barriers such as finances, sociocultural issues, structural features, and geography, which impede access to health care services and lead to poorer health outcomes among residents. Compared with their

OA02249). The Center for Community Health Development, research partner of the BVHP, is a member of the Prevention Research Centers Program, supported by the Centers for Disease Control and Prevention through cooperative agreement 5U48DP001924.

Conflict of interest: none declared.

Corresponding author: Whitney R. Garney, MPH, Center for Community Health Development, Texas A\&M School of Rural Public Health, 131 SRPH Administration Building, College Station, TX 77843-1266 (E-mail: wrgarney@srph. tamhsc.edu). 
urban counterparts, rural areas face a shortage of physicians and have financially unstable hospital systems. ${ }^{5}$ Ricketts ${ }^{5}$ illustrates this discrepancy by claiming that "rural America has $20 \%$ of the nation's population but less than $11 \%$ of its physicians." In addition to health care issues, rural areas often are characterized by higher rates of poverty, poorer educational attainment, greater transportation barriers, and higher rates of underinsured and uninsured populations. ${ }^{5}$ The disadvantages faced by rural populations are dire and even amid the revitalization that rural health care has undergone in the past years, disparities still exist. ${ }^{5}$ To address ongoing inequities, community perspectives are increasingly important in identifying unique contextual issues and developing locally tailored solutions that are effective and sustainable.

Our understanding of the importance of engaging communities in addressing local health issues is undergirded by decades of work from a variety of disciplines. The 1966 Folsom Report, developed by the National Commission on Community Health Services, introduced the idea of communities of solution (COSs). ${ }^{6}$ COSs alleviate the burden of health needs in their populations by proposing solutions from within. The COS inventories needs and resources to evaluate whether the issue at hand is manageable or if outside consultation is needed. These solutions are intrinsic to community-identified issues because the initiator has a deep understanding of the populations' needs and resources. ${ }^{7}$ The Folsom Report included a set of position statements to address 14 critical areas of concern regarding health care services, including (1) "health services and jurisdictional areas"; (2) "education for health"; (3) "volunteer citizen participation"; and (4) "action planning for community health services." In 2010, the World Health Organization echoed the Folsom Report when it identified 5 key elements to achieving better health outcomes: (1) reducing exclusion and social disparities; (2) organizing services around health needs and consumer expectations; (3) integrating health care into all sectors; (4) pursuing collaborative models of policy dialogue; and (5) increasing stakeholder participation. ${ }^{8}$ Using these recommendations, health initiatives led by community-based bodies of participation can locally accomplish solutions to reduce the health gaps that rural communities encounter.

The purpose of this article is to provide an overview of a case study of one region in Texas where multiple COSs mobilized resources to address similar issues in access to health care. This study highlights several community partnerships that help solve local health problems by comingling resources to induce improvements in population health.

\section{Emergence of the Brazos Valley Health Partnership}

In 2002, the Center for Community Health Development (CCHD), a Prevention Research Center associated with the Texas A\&M Health Science Center School of Rural Public Health, conducted a health status assessment of the Brazos Valley (BV), a 7-county region of central Texas comprising a suburban county (Brazos) surrounded by 6 rural counties (Burleson, Grimes, Leon, Madison, Washington, and Robertson). Figure 1 shows a graphical representation of the BV Region. The CCHD released the findings of the health status assessment in July 2002 at a regional health summit, with the purpose of dissem-

Figure 1. Map of the Brazos Valley region. CCHD, Center for Community Health Development. Reproduced with permission from Brazos Valley Council of Governments.

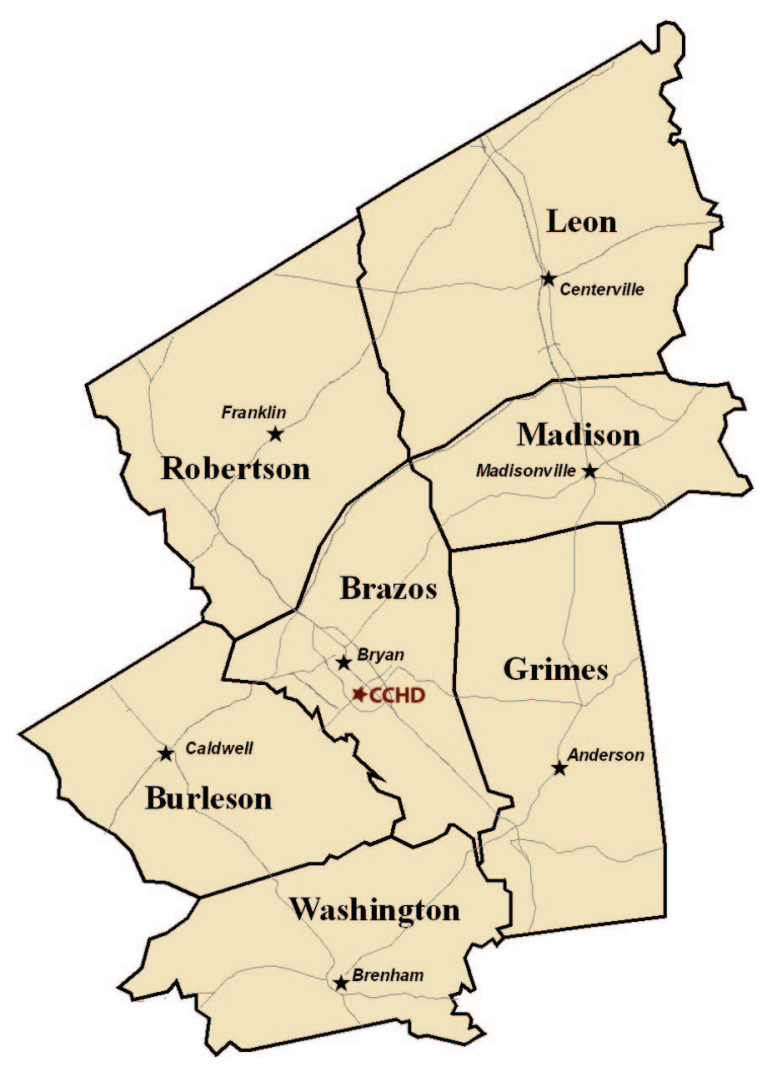


inating results to local stakeholders including policymakers, health care and social service providers, civic organizations, and educational institutions. The key findings revealed that rural residents face poorer access to health services and that their care is often fragmented. ${ }^{9}$ Summit participants, representing communities across the region, were asked to brainstorm potential solutions and ultimately organized themselves as a collaborative body identified as the BV Health Partnership (BVHP).

The BVHP adopted a mission to improve health status and access to care in the BV through the collaboration of services and the creation of local partnerships. ${ }^{9}$ As one of its first actions, the newly formed BVHP created task groups to develop recommendations on how to address (1) health status; (2) access to health care; (3) partnership development; and (4) information and referral needs. Over the next 90 days, these task groups formulated recommendations, which they presented in October 2002, yielding an access to care model called the health resource center.

The health resource center concept was designed to be a "one-stop shop" where multiple health and social service providers could be housed in the rural communities. ${ }^{10}$ Its purpose was to facilitate the delivery of services to rural residents; historically, these services were offered only in the BV region's suburban hub-roughly a 45- to 60-minute drive for most residents in the region. It also allowed providers to offer services in the rural counties at the resource center facility without incurring the overhead costs associated with having satellite offices in each of the rural counties. Conceptually, the resource center was mutually beneficial for all the stakeholders involved and alleviated some of the burden of access to care for rural residents.

Since the BVHP originated as a collaboration of more than 150 health and social service providers, they consulted with CCHD to help transition the health resource center concept into a tangible asset. ${ }^{10}$ Together, BVHP and CCHD elected that the first resource center would be piloted in rural Madison County because of its existing infrastructure, available resources, and demonstrated community support through local health care, government, and volunteer partners. In 2003, the partnership received seed money from the Health Resources and Services Administration to support the development of the health resource center, and in November 2003, the Madison Health Resource Center opened its doors.
After the pilot center was implemented and sustained, local leaders in Burleson, Grimes, and Leon Counties wanted to replicate the concept. Therefore, the model was expanded to Burleson County in 2004, Grimes County in 2005, and Leon County in 2006.

Since implementation, the health resource centers have recruited numerous service providers. For example, the Madison Health Resource Center houses and/or delivers services ranging from audiology, County Indigent Health Care, health education, hospice, information and referral, legal aid, medication assistance, mental health telecounseling, Senior Meals, service coordination and case management, transportation, Texas Families Together and Safe, services for abused children and their families, sexual assault resources, services to at-risk youth, and substance abuse telecounseling. ${ }^{11}$ In addition, the health resource centers have established an expansive client base. The average number of clients encounters per year at the resource centers range from 4059 clients in Leon County to 433 in Grimes County. ${ }^{11}$ Furthermore, the centers transport clients to health-related destinations, averaging 1145 rides per year. ${ }^{11}$ These results are documented annually in a return on community investment (ROCI) report, which each commission presents to their local county government. ${ }^{12}$ The ROCI reports document increased access to services and have been seen locally as evidence of the resource centers' worth, which in turn has ensured continued local funding to sustain the centers. ${ }^{12}$

The alliance between the BVHP and CCHD initially created a regional COS that developed and launched the health resource center concept. However, because the resource centers were implemented locally, the need for local leadership and resources became clear; thus, new COSs evolved within each of the rural counties. This evolution is an important part of the COS concept, which allows for the intermingling of outside resources in the application of intervention. ${ }^{6}$ Once the preliminary funding and resource center concept were executed, the BVHP's and CCHD's role shifted to one of technical assistance, leaving the leadership role in the hands of the local communities.

\section{Development of County Health Resource Commissions}

\section{Inception of the County Health Resource Commission}

One of the crucial components to the successful launch of the health resource centers was commu- 
nity involvement across multiple sectors, including county government, health care organizations, social service agencies, churches, and local businesses. This element also assisted in establishing the sustainability of the resource centers after their initial inception. All resource centers were, and are still, funded by financial and in-kind resources, through the local county and city governments, local critical access hospitals, and donations from benefactors. However, soon after each resource center opened, the need for formal oversight to advise and strategically direct the centers emerged. In response to this need, one of the original resource center stakeholders, the Burleson County judge, suggested establishing county health resource commissions as formal governing bodies to the resource centers and advisors to the counties' health-related issues. As a result, in May 2005 the Burleson County Commissioners' Court formally appointed the Burleson County Health Resource Commission. Shortly thereafter, the Leon County Commissioners' Court appointed the Leon County Health Resource Commission and a year later, in 2006, Grimes and Madison Counties followed suit. This organic progression was the first step in the process that recognized the rural counties as COSs.

\section{Membership Makeup of the County Health Resource Commissions}

The commissions consist of volunteer representatives from diverse sectors across the community. The commissioners are of various racial and ethnic backgrounds, professional sectors, and geographic reaches within the community. Figure 2 provides a more detailed breakdown of each county and their respective commission characteristics.

Commission members serve a 2-year term at the discretion of the County Commissioners' Court. They may be re-elected for a maximum of 3 successive terms. In addition, each commission has majority-elected officer positions including a chair, vice chair, secretary, and treasurer. Officers are responsible for meeting planning and preparation. All 4 commissions meet on a reoccurring basis, either quarterly or bimonthly, depending on their personal preference.

\section{Role of the County Health Resource Commissions and Their Staff}

The Commissions are responsible for overseeing health resource center operations and personnel, as well as providing direction through strategic planning, allocating resources, and coordinating and expanding services related to countywide health concerns. The commissions serve as a liaison to the County Commissioners' Courts, as their advisory body on the health of their communities. In addition, all 4 established commissions collaborate with the CCHD and BVHP to conduct regular health status assessments every 4 years; following the 2002 assessment, additional assessments were conducted in 2006 and 2010. ${ }^{9-11}$ The comprehensive, local health data provide the foundation for setting priorities, strategic planning, and activities that the commissions and other health-focused community and academic organizations pursue. ${ }^{9-11}$

To govern day-to-day operations, each commission has developed operational policies and proce-

Figure 2. County health resource commission chart.

\begin{tabular}{|c|c|c|c|c|}
\hline & Burleson County & Grimes County & Madison County & Leon County \\
\hline Total Population & 17,251 & 26,887 & 13,747 & 16,916 \\
\hline Top 5 Community Issues & $\begin{array}{l}\text { 1. Transportation } \\
\text { 2. Lack of jobs } \\
\text { 3. Unemployment } \\
\text { 4. Illegal drug use } \\
\text { 5. Lack of recreational and } \\
\text { cultural activities }\end{array}$ & $\begin{array}{l}\text { 1. Transportation } \\
\text { 2. Unemployment } \\
\text { 3. Lack of jobs } \\
\text { 4. Illegal drug use } \\
\text { 5. Sewage and storm } \\
\text { water drainage }\end{array}$ & $\begin{array}{l}\text { 1. Transportation } \\
\text { 2. Illegal drug use } \\
\text { 3. Lack of recreational and } \\
\text { cultural activities } \\
\text { 4. Alcohol abuse } \\
\text { 5. Property crime }\end{array}$ & $\begin{array}{l}\text { 1. Transportation } \\
\text { 2. Lack of recreational and } \\
\text { cultural activities } \\
\text { 3. Illegal drug use } \\
\text { 4. Access to medical services } \\
\text { 5. Lack of jobs }\end{array}$ \\
\hline $\begin{array}{r}\text { Number of County Health } \\
\text { Resource Commission } \\
\text { Members and Staff }\end{array}$ & 13 & 15 & 15 & 26 \\
\hline $\begin{array}{l}\text { Sectors Represented by } \\
\text { Commission Members }\end{array}$ & $\begin{array}{l}\text { Healthcare } \\
\text { Churches } \\
\text { Government (City, County) } \\
\text { Law Enforcement } \\
\text { Banking } \\
\text { Education }\end{array}$ & $\begin{array}{l}\text { Healthcare } \\
\text { Churches } \\
\text { Government (City, County) } \\
\text { Agrilife Extension } \\
\text { Local Business }\end{array}$ & $\begin{array}{l}\text { Healthcare } \\
\text { Churches } \\
\text { Government (County) } \\
\text { Banking } \\
\text { Education } \\
\text { Accounting/Law }\end{array}$ & $\begin{array}{l}\text { Healthcare } \\
\text { Chamber of Commerce } \\
\text { Churches } \\
\text { Government (City, County) } \\
\text { Food Bank } \\
\text { Non-profits }\end{array}$ \\
\hline $\begin{array}{l}\text { Racial/Ethnic Makeup of } \\
\text { Commission Members }\end{array}$ & $\begin{array}{l}\text { White: } 69 \% \\
\text { Black: } 15 \% \\
\text { Hispanic: } 15 \%\end{array}$ & White: $100 \%$ & $\begin{array}{l}\text { White: } 71 \% \\
\text { Black: } 14 \% \\
\text { Hispanic: } 14 \%\end{array}$ & $\begin{array}{l}\text { White: } 85 \% \\
\text { Black: } 15 \%\end{array}$ \\
\hline
\end{tabular}


dures and hired personnel in the form of a full-time executive director and part-time office manager. The personnel and health resource center activities are funded by external sources, including local critical access hospitals, city and county government, and patron donations. Personnel report to the commission and execute tasks involving the management of the resource center operations and plan and coordinate activities for the commission. Staff also provides service coordination, case management, information, and referrals; coordinates transportation for resource center clients; and runs various health-related programs offered through the centers.

\section{Community Response: Increasing Access to Health Care}

While the identified health issues within each county and the actions the commissions chose to implement to address such challenges vary, overall the commissions have succeeded in many efforts to increase access to care in their communities. ${ }^{9-11}$ Described below are two illustrative examples of how the commissions have demonstrated their capacity to be a conduit of solution within their communities. These two examples serve to explain how the commissions work, not to encompass all the activities that they pursue.

\section{County Health Resource Commissions in Action}

The 2006 BV Health Status Assessment identified lack of access to mental health care services as an issue in several of the rural counties. ${ }^{10}$ As a result, the Leon County Health Resource Commission and leaders within the county government chose to make mental health a priority. They set in motion a plan to pursue funding to establish a sustainable solution for Leon County residents in need of mental health care services. With the help of the CCHD, the Leon County Health Resource Commission identified a viable solution by delivering mental health care through telehealth counseling services. The project began by initiating a partnership between the commission, the county government, the CCHD, and the Texas A\&M University (TAMU) Department of Educational Psychology. ${ }^{13}$ In 2007, the Office of Rural Health Policy awarded funds to Leon County to implement the telehealth-based counseling program. The program utilized a doctoral student in TAMU's Coun- seling Psychology Program to conduct assessments and provide counseling therapy from his location in Brazos County via a high-definition, secure televideo, which was connected to the Leon Health Resource Center. To date, the service has been used by more than 770 clients and has alleviated client distress, met expectations of referral sources and community stakeholders, decreased patients' depressive symptoms, and increased mental health composite scores. ${ }^{13}$ Since the only ongoing cost for Leon County was a fiber optic telephone line to maintain the telehealth capabilities for the resource center (about $\$ 5,000$ per year), the program was sustained after grant funding ended and has been a conduit for mental health care service delivery in Leon County ever since. In addition, the partnership with TAMU's Department of Educational Psychology has thrived because the program allows TAMU students to receive necessary training, which is part of their degree program. In fact, increased use of services spurred the department to obtain an additional doctoral student to meet the growing counseling needs. ${ }^{13}$

After implementation in Leon County, the Madison County Health Resource Commission chose to replicate the concept. ${ }^{13}$ However, instead of focusing solely on increasing access to mental health care services, the commission expanded the focus to include substance abuse services and community health outreach into the county's Hispanic population, both of which were issues in the 2010 BV Health Assessment. ${ }^{11}$ The Madison commission initiated a partnership between the Madison County government, the Madison St. Joseph Critical Access Hospital, TAMU's Department of Educational Psychology, and the CCHD. The county and its network of providers applied for funding and in 2012 were awarded grant funds from the Office of Rural Health Policy. Development of the program's infrastructure is underway and service delivery is scheduled for early 2013 .

\section{Community Response to the County Health Resource Commissions}

The counties recognize the value of the commissions and their actions to support the resource centers. ${ }^{12}$ The Leon County Judge, Byron Ryder, represents the thoughts of local government in thinking that the Leon County Health Resource Commission's efforts to improve access to health care in their community is a tremendous asset. 
Judge Ryder and his colleagues believe that the commission and resource center has brought new venues of health care into Leon County and has reached residents who need services, but would not normally be able to access them. Local community perception is that one of the most important aspects of the commission is its ability to bring together partnerships to address specific issues, which is a reiteration of the Folsom Report. ${ }^{6,14}$

As documented in ROCI reports, the value of health resource center services leveraged compared with the amount of funds expended have increased throughout the years, which have been seen locally as a success. In addition, the CCHD has measured the success of the COS through key partner interviews and changes in interorganizational network relationships, which are methods of evaluation commonly used in capacity-building initiatives. ${ }^{14,15}$

However, the clearest representation of the communities' response to their local COS is seen when the commissions confront health concerns throughout the county. Each regional health status assessment conducted in the BV allows local residents to voice their anxieties about the health of their communities through community discussion groups. ${ }^{10}$ Each commission then uses this information to formulate health priorities that represent their constituents' concerns. As a result, multiple partnerships have emerged between the commissions and other community organizations to increase access to services for transportation, child protection, lack of housing, access to physical ac- tivity, and senior nutrition. These regional interactions reflect the suggestion in the Folsom Report that local partnerships be initiated in response to a problem, rather than a set of overarching priorities. ${ }^{6}$ The upsurge of working partnerships and the ability to act are valuable contributions that the commissions offer their communities; in return, their efforts are respected and perceived as beneficial to the communities in which they reside. ${ }^{11}$ Figure 3 presents a visual representation of the activities of the COS.

\section{Discussion}

To increase access to health care within the BV, the health resource commissions serve as action planning bodies for community health issues and provide health education and resources for their community's residents through their main outreach endeavor-the health resource centers. These functions, as well as the overall premise of the commissions, which is to be a venue of voluntary citizen participation for residents to impact their community's health, are congruent with the recommendations in the Folsom Report and coincide with the 2010 directives of the World Health Organization. ${ }^{6,8}$ The BVHP also serves as a broader COS, bringing the local health resource commissions together to share information, leverage resources, and coordinate strategies when appropriate.

The examples provided in this article underscore how a concept manifested within a unique commu-

Figure 3. Timeline of Communities of Solution (COS) Activities. BVHP, Brazos Valley Health Partnership; HCAP, \#\#\#; ORHP, \#\#\#.

\begin{tabular}{|c|c|c|c|c|c|c|}
\hline 2002 & 2003 & 2004 & 2005 & 2006 & 2010 & 2012 \\
\hline $\begin{array}{l}\text { - Health Status } \\
\text { Assessment } \\
\text { - Health } \\
\text { Summit(7/02) } \\
\text { - Brazos Valley } \\
\text { Health } \\
\text { Partnership } \\
\text { Formed } \\
\text { - Task forces } \\
\text { reconvened } \\
\text { (10/02) }\end{array}$ & $\begin{array}{l}\text { - BVHP received } \\
\text { HCAP grant } \\
\text { - Madison Health } \\
\text { Resource } \\
\text { Center opened } \\
(11 / 03)\end{array}$ & $\begin{array}{l}\text { Burleson } \\
\text { Health } \\
\text { Resource } \\
\text { Center } \\
\text { opened }\end{array}$ & $\begin{array}{l}\text { - Grimes Health } \\
\text { Resource } \\
\text { Center opened } \\
\text { - Burleson } \\
\text { Health } \\
\text { Resource } \\
\text { Commission } \\
\text { established } \\
\text { - Leon Health } \\
\text { Resource } \\
\text { Commission } \\
\text { established }\end{array}$ & $\begin{array}{l}\text { - Leon Health } \\
\text { Resource } \\
\text { Center opened } \\
\text { - Health Status } \\
\text { Assessment } \\
\text { - Telehealth } \\
\text { ORHP grant } \\
\text { award to Leon } \\
\text { County } \\
\text { - Madison Health } \\
\text { Resource } \\
\text { Commission } \\
\text { established } \\
\text { - Grimes Health } \\
\text { Resource } \\
\text { Commission } \\
\text { established }\end{array}$ & $\begin{array}{l}\text { Health Status } \\
\text { Assessment }\end{array}$ & $\begin{array}{l}\text { Telehealth } \\
\text { ORHP grant } \\
\text { awarded to } \\
\text { Madison } \\
\text { County }\end{array}$ \\
\hline
\end{tabular}


nity context - in this case, a rural community — can be used to mobilize solutions in response to locally identified issues. In this instance, the COS initially was the entire 7-county region, bringing together a broad array of representatives to determine an overarching strategy for extending existing health resources to the rural areas within the region. As this overarching strategy was operationalized, it became clear that more localized COSs were better suited to implementing activities at the county level.

When considering a case study like this one, it is important to recognize the differences between the populations involved and consider how the unique context of each community affects the COS and the strategies used to address identified health issues. ${ }^{10}$ It is clear that county boundaries are irrelevant with regard to certain social and health issues that residents face. The "problem shed," or area encompassing all affected stakeholders for any of these issues, typically does not fall exactly on any geopolitical boundary. ${ }^{16}$ From a pragmatic viewpoint, however, COSs must engage people and mobilize resources to address the issue. In the $\mathrm{BV}$, this was done at the county level, although adjacent counties sometimes adopted the effective practices of its neighbors to address similar issues.

The counties involved range in population from approximately 13,747 to 26,837 , with a variety of incorporated areas, differences in resource availability, and varying demographics. Thus, the composition of the commissions range in size (from 13 to 26 members) and represent different community sectors, depending on which of those sectors is a key stakeholder or resource-holder in the community. Each commission independently determines appropriate leadership to accomplish its goals, and varying leadership structures emerged in each community. In Burleson County, the county judge mobilized the initial effort, and the director of the resource center became particularly influential in decision making because of his expertise and interaction with residents, even though he was not a resident of the local community. Similarly, the director of the Madison County commission was able to mobilize volunteers and support local initiatives, and the members of the commission became increasingly active in local activities. In Leon County, the county judge and one commissioner provided leadership and strong support, but the executive director emerged as the person to convene stake- holders and implement activities. Grimes County had less support at the county level and struggled with identifying someone to champion their activities, which resulted in more difficult maintenance of services and slower growth; they were able to garner support from the government of the city in which the resource center is located. As the commissions evolved, each went through iterations of determining the leadership structure that fit their community and figuring out how to plan and execute strategies to improve health issues as they arose. Ultimately, it did not matter if the local champion was a formal or informal leader-they just had to be someone with influence willing to advance the community's health agenda.

\section{Measurement Challenges}

One key challenge inherent in the evolution of these regional and local COSs is measurement-of the effectiveness of the oversight bodies as well as the impact they make on the health of their communities. Fortunately, the research partnership with the CCHD has enabled measurement that likely exceeds what similar COSs that lack such a partnership could capture. Over the past 10 years, measures have focused on several key areas:

- Population health status through the BV Health Status Assessments that occurs every 4 years ${ }^{15}$;

- How interorganizational networks have developed and the resulting effects on collaboration and coordination, measured by surveys conducted at regular intervals ${ }^{14}$;

- Effects of community health development activities on community capacity, through qualitative and quantitative measures ${ }^{17}$;

- Partner experiences in working together to address health issues, gathered through semistructured interviews ${ }^{18}$; and

- ROCI analysis conducted by the CCHD and presented back to the commissions annually.

Many of the key factors critical to the success of these COSs are difficult to operationalize and measure, but these partners continue to ask questions and develop ideas for how to access information that will increase our understanding of what works and why.

As mentioned, the partnership of the BVHP and the commissions with the CCHD is unique and allows for access to a range of expertise, resources, 
and technical assistance that may not commonly be available to other such partnerships. In addition to the CCHD and the university as resources, each community has worked to identify local champions to lead efforts and make connections within the community to mobilize key resources outside the community, which enhances their collective ability to solve problems. Finally, the local governments in each community demonstrated substantial support for the commissions and their activities. These unique factors may be considered a limitation in the generalizability of any lessons or findings resulting from this case study, but they may also indicate elements that are critical to the success of similar efforts. Although the each community is unique, we learned that identifying and engaging a local leader, mobilizing local resources, and implementing practical solutions that also fit the dynamics and values of a community are common factors in sustainable community change.

\section{Conclusion}

This case study provides nested examples of COSs that evolved from local and regional levels to address disparities in access to care for rural residents. Their experience indicates that not all problemsespecially complex problems-can be addressed internally; clearly, COSs sometimes are required to access external resources in their attempts to address community problems and concerns. However, what is also clear and perhaps of most importance is that solutions that originate with the community continue to be the most effective and sustainable over time.

\section{References}

1. Eberhardt M, Ingram D, Makuc D, Pamuk E, Freid V, Harper S. Health, United States, 2001. Urban and rural health chartbook. Hyattsville, MD: National Center for Health Statistics; 2001. Available from http://www.cdc.gov/nchs/data/hus/hus01cht. pdf; accessed March 11, 2013.

2. Stange KC. The problem of fragmentation and the need for integrative solutions. Ann Fam Med 2009; 7:100-3.

3. Hartley D. Rural health disparities, population health, and rural culture. Am J Public Health 2004; 94:1675-8.

4. Phillips C, McLeroy K. Health in rural America: Remembering the importance of place. Am J Public Health 2004;94:1661-3.
5. Ricketts TC. The changing nature of rural health care. Ann Rev Public Health 2000;21:639-57.

6. National Commission on Community Health Services. Health is a community affair. Cambridge: Harvard University Press; 1966.

7. Folsom Group. Communities of solution: the Folsom Report revisited. Ann Fam Med 2012;10: 250-60.

8. World Health Organization. WHO primary health care. Geneva: WHO; 2010.

9. Community Health Development Program. Brazos Valley health status assessment executive summary. College Station, TX: School of Rural Public Health; 2002.

10. Center for Community Health Development. 2006 Brazos Valley health status assessment: executive report. College Station, TX: School of Rural Public Health; 2006.

11. Center for Community Health Development. Brazos Valley health assessment: executive report. College Station, TX: School of Rural Public Health; 2010.

12. Madison Health Resource Center. Return on community investment report. Madisonville, TX: Madison County; 2012.

13. McCord C, Elliott T, Wendel M, Brossart D, Cano M, Gonzales G, Burdine J. Community capacity and teleconference counseling in rural Texas. Prof Psychol Res Pract 2011;42:521-7.

14. Wendel ML, Prochaska JD, Clark HR, Sackett S, Perkins K. Interorganizational network changes among health organizations in the Brazos Valley, Texas. J Prim Prev 2010;31:59-68.

15. Felix M, Burdine J, Wendel ML, Alaniz A. Community health development: a strategy for reinventing America's health care system one community at a time. J Prim Prev 2010;31:9-19.

16. Kneese AV. The "problem shed" as a unit for environmental control. Arch Environ Health 1968;16:124-7.

17. Wendel ML, Alaniz A, Kelly BN, Clark HR, Drake KN, Outley CW, Garney W, Dean K, Simpson L, Allen B, Finke P, Harris T, Jackson V, Player D, Ramirez A, Sutherland M, Viator C, McKyer ELJ, St. John JA, McLeroy KR, Burdine JN. Capacity building in rural communities. In: Crosby RA, Wendel ML, Vanderpool RC, Casey BR (eds). Rural populations and health: determinants, disparities, and solutions. San Francisco: Jossey-Bass Wiley; 2012:215-35.

18. Garney W, Alaniz A, Clark A, Wendel M, Allen B, Viator C. Evaluating capacity building and sustainable partnership: Brazos Valley Health Partnership. Poster presented at the 2012 Community-Campus Partnerships for Health Conference, Houston, TX, April 18-21, 2012. 